\title{
Individual-level needle and syringe coverage in Melbourne, Australia: a longitudinal, descriptive analysis
}

Daniel O'Keefe ${ }^{1,2^{*}}$, Nick Scott ${ }^{1,2}$, Campbell Aitken ${ }^{1,2}$ and Paul Dietze ${ }^{1,2}$

\begin{abstract}
Background: Coverage is used as one indicator of needle and syringe program (NSP) effectiveness. At the individual level, coverage is typically defined as an estimate of the proportion of a person who injects drugs' (PWID) injecting episodes that utilise a sterile syringe. In this paper, we explore levels of individual syringe coverage and its changes over time.
\end{abstract}

Methods: Data were extracted from 1889 interviews involving 502 participants drawn from the Melbourne drug user cohort study (MIX).

We asked questions relating to participants syringe acquisition, distribution and injecting frequency within the two weeks before interview. We created a dichotomous coverage variable that classified participants as sufficiently $(\geq 100 \%)$ covered if all their injecting episodes utilised at least one sterile syringe, and insufficiently $(<100 \%)$ covered if not. We categorised participants as "consistently covered" if they were sufficiently covered across interviews; as "consistently uncovered" if they were insufficiently covered across interviews; and "inconsistently covered" if they oscillated between coverage states. Chi-square statistics tested proportions of insufficient coverage across sub-groups using broad demographic, drug use and service utilisation domains. Logistic regression tested predictors of insufficient coverage and inconsistently covered categorisation.

Results: Across the sample, levels of insufficient coverage were substantial (between 22-36\% at each interview wave). The majority (50 \%) were consistently covered across interviews, though many (45\%) were inconsistently covered. We found strong statistical associations between insufficient coverage and current hepatitis C virus (HCV) infection (RNA +). Current prescription of opioid substitution therapy (OST) and using NSPs as the main source of syringe acquisition were protective against insufficient coverage.

Conclusion: Insufficient coverage across the sample was substantial and mainly driven by those who oscillated between states of coverage, suggesting the presence of temporal factors. We recommend a general expansion of NSP services and OST prescription to encourage increases in syringe coverage.

Keywords: Injecting drug use, Syringe coverage, Harm reduction, Longitudinal analysis

Abbreviations: AOR, Adjusted odds ratio; BBV, Blood-borne virus; 95 \% Cls, 95 \% Confidence intervals; HCV, Hepatitis C virus; IQR, Interquartile range; MIX, Melbourne injecting drug user cohort study; NSP, Needle and syringe program; OST, Opioid substitution therapy; PWID, People/person who injects drugs; WHO, World Health Organisation

\footnotetext{
* Correspondence: daniel.okeefe@burnet.edu.au

${ }^{1}$ Centre for Population Health, Burnet Institute, 85 Commercial Rd,

Melbourne, VIC 3004, Australia

${ }^{2}$ School of Public Health and Preventive Medicine, Monash University, 99

Commercial Rd, Melbourne, VIC 3004, Australia
}

(c) 2016 The Author(s). Open Access This article is distributed under the terms of the Creative Commons Attribution 4.0 International License (http://creativecommons.org/licenses/by/4.0/), which permits unrestricted use, distribution, and reproduction in any medium, provided you give appropriate credit to the original author(s) and the source, provide a link to the Creative Commons license, and indicate if changes were made. The Creative Commons Public Domain Dedication waiver (http://creativecommons.org/publicdomain/zero/1.0/) applies to the data made available in this article, unless otherwise stated. 


\section{Background}

The coverage of a public health program can be defined as the extent to which it reaches its intended population [1]. It is an indicator of the effectiveness of public health interventions in reducing public health risks.

Needle and syringe programs (NSPs) seek to avert blood-borne virus (BBV) spread amongst people who inject drugs (PWID) via the distribution of sterile needles and syringes (hereafter referred to as syringe/s). The coverage achieved by NSPs at the population level refers to the proportion of PWID reached by services. At the individual level, coverage is typically defined as the proportion of a PWID's injecting episodes that utilise a sterile syringe [2].

The sharing of used syringes is a significant contributor to the transmission of BBVs amongst PWID [3, 4]. It is estimated that globally, only 1-4 syringes are distributed per PWID per month [5], well below the World Health Organization (WHO) recommended rate of 200 syringes per PWID per year [6].

Syringe coverage is mediated by context. Service management and funding [7], dispensation policy [8], intensive policing practices [1, 9], cohesiveness of PWID networks [2], spatial service access [10], and individual demographics $[11,12]$ influence the ability of individuals to attain sufficient syringes and service systems to provide sufficient coverage.

Previous research has shown that insufficient coverage at the individual level is significantly associated with highfrequency injecting and not using NSPs as a primary source of syringe acquisition [2]. Insufficient individuallevel coverage has also been associated with syringe re-use and receptive/distributive syringe sharing [11-13]. Despite these findings, current understanding of the causes of insufficient coverage is poor. Most research on individual coverage has been cross-sectional and consequently unable to capture variation over time - hence Bluthenthal et al.'s call for longitudinal investigation [11]. A greater understanding of coverage over time will also provide better knowledge of the predictors of insufficient coverage and enable better interventions.

The Australian context provides the ideal setting for research on patterns of syringe coverage over time. Australia's early and comprehensive adoption of NSPs prevented an HIV epidemic in PWID, in contrast to many other countries $[14,15]$. An estimated $3000+$ syringe outlets service an estimated population of 90,000 PWID [16], distributing approximately 213 syringes per PWID per year [12], in excess of WHO population-level recommendations [6]. Despite greater opportunity to acquire syringes than many of their international counterparts, an estimated 16$37 \%$ of Australian PWID experience insufficient coverage $[2,12,17]$. Consequently, research exploring the individual and structural determinants of insufficient coverage in Australia provides important information for other settings.
In this paper we analyse six years of data from an ongoing cohort of PWID in Melbourne, Australia. We aim to:

- describe the characteristics of individuals with recent insufficient coverage (insufficient syringe acquisition to cover injecting episodes within the past two weeks) across broad demographic, drug use and service utilisation domains;

- explore how the proportion of individuals with recent insufficient coverage changes over time;

- categorise participants according to their longitudinal patterns of coverage; and

- identify exposure sub-groups independently associated with individual coverage and longitudinal coverage pattern trajectories.

\section{Methods}

\section{Melbourne injecting drug user cohort study}

Data are drawn from the Melbourne injecting drug user cohort study (MIX), which has been described in detail elsewhere [18]. The cohort includes PWID recruited through the original MIX recruitment phase in 2008$2010(n=688)$, and those rolled into the study in 2011 via past involvement in the Networks II cohort $(n=69)$ [19], resulting in 757 participants. Both MIX and Networks II sought to recruit regular injectors, and despite some demographic differences between the MIX and Networks II cohorts at the 2011 roll-in (mean age in 2011 was 29 in MIX, 35 in Networks II; 16 \% in MIX were born overseas, $31 \%$ in Networks II; $54 \%$ were currently on OST in MIX, 62 \% in Networks II), the characteristics of the cohorts at baseline (2005 for Networks II) were comparable [19-21].

Eligibility criteria for the original MIX cohort were being aged 18-30 years and reporting injecting of heroin and/or methamphetamine regularly (at least once a month in the six months prior to recruitment).

\section{Participant sample}

As of February 2015 (dataset end), 2862 separate interviews had been collected over a maximum of seven annual interview waves per participant. As the necessary coverage questions were not introduced into the questionnaire until June 2010, all interviews prior to this date (902 interviews, 184 participants) were excluded from analysis. Furthermore, as we intended to analyse changes to coverage longitudinally, only participants with two or more interviews after June 2010 were retained, excluding a further 71 participants. This process resulted in an amended dataset of 502 participants and 1889 interviews across a maximum of six separate interview waves. Study retention was high, with $85 \%$ of these participants having at least three interviews. 
The demographic and drug use patterns of the total cohort and the amended sample used in analysis were similar, though current employment was 7 percentage points higher, and current OST prescription 21 percentage points higher, among the amended sample. Comparisons between the two sets of data at first interview are presented in Additional file 1.

\section{Measures}

To measure syringe retention, we asked the following questions:

"In the last two weeks, how many new syringes in total did you get?"

"In the last two weeks, how many syringes did you give away or sell to others?"

The MIX questionnaire records past week use and injecting frequency for 18 drug types. Past week injecting frequencies for each drug type were summed to create a total injecting frequency variable.

Using a method of calculating individual syringe coverage adapted from Bluthenthal et al. [11], we subtracted the number of syringes sold or given away from the number of syringes acquired. We then multiplied past week injecting frequency by two to create a consistent time frame for the measure (rather than syringe collection being halved, as initial inspection showed less variance for injection frequency, suggesting it is the more consistent practice). We then divided the number of syringes retained by past two-week injecting frequency and then multiplied by 100 , resulting in a percentage of injecting episodes that utilised a sterile syringe. The formula for individual coverage measurement was therefore:

$$
\frac{(\text { syringes acquired-syringes distributed })}{(\text { past week injecting frequency } \times 2)} \times 100
$$

Recent individual coverage was considered to be sufficient if every reported episode of injecting was covered by at least one reported sterile syringe, or $\geq 100 \%$ individual coverage. A dichotomous variable, "recent coverage" ( $\geq 100 \%$ coverage / $<100 \%$ coverage), was applied to each interview with valid data, classifying participants as either sufficiently or insufficiently covered for the two weeks before interview.

Coverage was only calculated for participants who reported both syringe acquisition and injecting within the two-week period (as the absence of either parameter precludes calculation). Missing data accounted for $44 \%$ (832 observations) of all coverage responses. Of these missing data, most (602 observations, $72 \%$ of all missing responses) resulted from injecting abstinence.

\section{Sub-group selection}

We chose exposure variables a priori, including predictors in Bluthenthal et al.'s [11] original coverage paper and recent work by McCormack et al. [17]. Broadly, these subgroups fall within demographic, drug use characteristics and service utilisation domains. Demographic: "sex" (male/female), "Indigenous status" (yes/no), "WHO definition of youth" ( $\leq 24$ years/ $>24$ years); "highest level of education" (<year 10/year 10-11/year 12, higher education, trade), "weekly income" (around median: $<\$ 400 / \geq \$ 400$ ), "employment status" (employed/unemployed), "stable accommodation" (yes/no), "country of birth" (Australia/ other), "arrest (past twelve months)" (yes/no). Drug use characteristics: "injecting career" (around median: $<13$ years/ $\geq 13$ years), "heroin injection (past month)" (yes/ no), "methamphetamine injection (past month)" (yes/no), "Hazardous drinking scale score - derived from Audit-C scale" (abstinent $/<8$ points $/ \geq 8$ points) [22], "receptive syringe sharing (past month) - derived from BBV-TRAQ-SV" (yes/no), "injection of another person (past month) - derived from $B B V-T R A Q-S V$ " (yes/no), "been injected by another person (past month) - derived from $B B V$-TRAQ-SV" (yes/no), "BBV-TRAQ-SV injecting risk scale score" (continuous measure) [23], "hepatitis $\mathrm{C}$ virus serology (HCV) status" (three categories: positive (RNA+)/exposed (Antibody+, RNA-)/negative (Antibody-, RNA-), "injecting more than usual in the past six months" (yes/no), "solitary injecting $>80 \%$ of the time" (yes/no). Service utilisation: "current opioid substitution therapy prescription (OST)" (yes/no), "NSP as usual source of syringe acquisition (past month)" (yes/no). An amended version of the MIX questionnaire, relevant to this analysis, is presented in Additional file 2: Appendix 1.

\section{Analysis strategy}

We categorised participants with at least two instances of valid coverage data into three distinct subgroups according to longitudinal experience of the dichotomised recent coverage variable: "consistently covered" if all valid coverage data was recorded as sufficient, "consistently uncovered" if all valid coverage data was recorded as insufficient, and "inconsistently covered" if participants had at least one change between the two states of coverage across interviews.

The three coverage pattern groups were comparable in terms of missing data and attrition patterns. In the consistently covered group, $91 \%$ of participants had three or more interviews and $27 \%$ missing coverage data. In the consistently uncovered group, $82 \%$ had three or more interviews and $26 \%$ missing data. The inconsistently covered group had $92 \%$ with three or more interviews and $22 \%$ missing data.

\section{Statistical analysis}

Proportional differences between participants experiencing sufficient or insufficient coverage at their first interview and 
their most recent interview were tested using chi-square statistics for categorical variables and Wilcoxon rank-sum testing for non-parametric continuous variables. Proportional differences between the three coverage pattern groups at first interview were tested using chi-square statistics for categorical variables and Kruskal-Wallis testing for non-parametric continuous variables.

Logistic regression was used to determine cross-sectional predictors of insufficient coverage from the dichotomous recent coverage variable. Initial inspection suggested that a binary coverage pattern variable of consistently covered/inconsistently covered be examined (placement in the inconsistently covered group as the outcome of interest), with too few cases of those consistently uncovered to allow analysis. The chosen time point of analysis was the first interview for each participant so as to minimise any bias across time due to differences in number of interviews.

Statistical significance was set at $p<0.05$. All analyses were carried out using Stata 13.1 for Windows (StataCorp LP, TX, USA).

\section{Results}

\section{Participant demographics}

At first interview, the amended sample of 502 participants was predominately male (64\%), Australian-born (82 \%), largely non-indigenous (95\%), unemployed (78 \%) and living in stable accommodation (85\%). Mean age at first interview was 30. For those reporting injecting within the month prior to interview $(n=416)$, heroin was the most commonly injected drug (73\%), followed by methamphetamine $(11 \%)$. The remaining $16 \%$ of participants most commonly injected either some form of OST or other pharmaceutical opioid.

\section{Coverage characteristics across the cohort}

Participants who reported syringe acquisition in the two weeks before interview collected syringes from any source a median of two times (interquartile range (IQR): $1-3)$ at both first and most recent interview. Participants collected a median of 20 syringes at first and most recent interview (IQRs of 10-70 and 10-100 respectively), and gave away/sold a median of one syringe (IQR: 0-8) at first interview and zero syringes (IQR: 0-10) at most recent interview. After subtraction of distributed syringes, participants retained a median of 16 syringes at both their first and most recent interview (IQRs of 6-48 and 5-65 respectively).

For those not reporting injecting abstinence in the week before interview, median self-reported injecting frequency was five times (IQR: 2-11) at both first and most recent interview (IQR: 2-14).

Median coverage percentages at first and most recent interview were $165 \%$ (IQR: 92-353\%) and $175 \%$ (IQR: 100-357 \%) respectively. Despite the median percentage coverage being greater than $100 \%$, recent insufficient coverage was substantial; $26 \%$ and $25 \%$ of the sample were insufficiently covered at their first and most recent interview respectively.

The percentages of participants with recent sufficient coverage across all interviews are presented in Fig. 1.

\section{Cross-sectional sufficient/insufficient coverage across exposure sub-groups}

Proportions of sufficient and insufficient coverage were stable over time across many sub-groups. Those with insufficient coverage were more likely to report episodes of increased injecting frequency lasting $\geq 1$ month in the past six months $\left(X^{2}=4.28, p=0.039\right)$ and recent injection of methamphetamine $\left(X^{2}=15.18, p=<0.001\right)$. Those with sufficient coverage were more likely to report injecting careers equal to or longer than 13 years $\left(X^{2}=15.63, p=<0.001\right)$ and current OST prescription $\left(X^{2}=12.11, p=0.001\right)$. These findings were significant at most recent interview, but not at first interview.

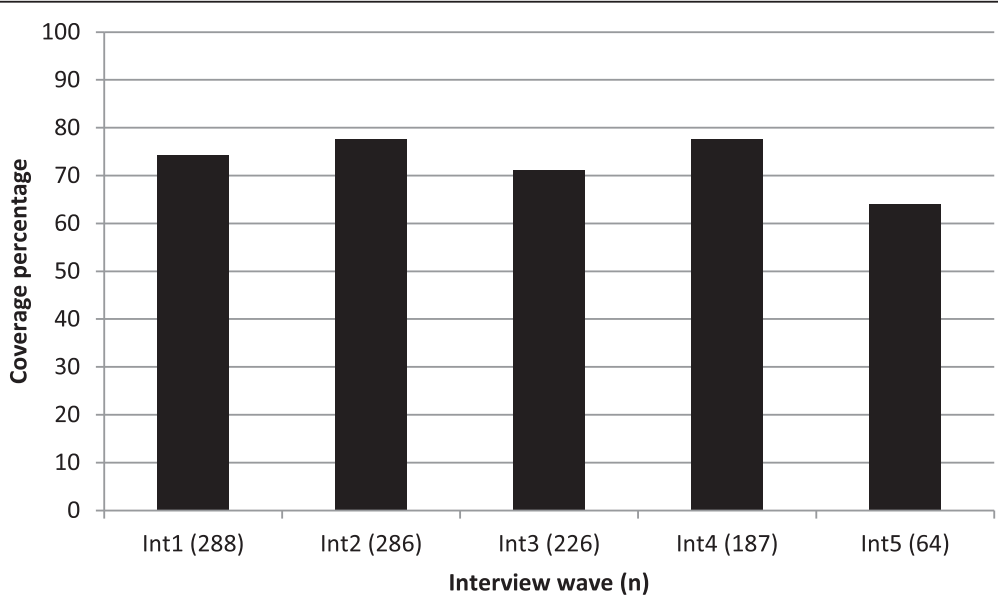

Fig. 1 Percentages of sufficient coverage across interview waves 
Participants arrested within the past twelve months were more likely to report insufficient coverage at first interview $\left(X^{2}=3.91, p=0.048\right)$, but not at most recent.

Insufficient coverage was also associated with risk practices. Those with insufficient coverage were more likely to report receptive syringe sharing within the past month at first interview $\left(X^{2}=7.49, p=0.006\right)$. Furthermore, those with insufficient coverage recorded higher injecting risk scores on the BBV-TRAQ-SV scale at both interviews, a difference that was significant at most recent interview $(p=0.022)$, but not first.

At first interview, participants with current $\mathrm{HCV}$ infection were more likely to report insufficient coverage $\left(X^{2}=8.78, p=0.012\right)$. This finding was confirmed in regression analysis, which identified greater odds of insufficient coverage for those with a current $\mathrm{HCV}$ infection (adjusted odds ratio $(\mathrm{AOR}))=4.44$ (95\% confidence intervals (CIs): 1.43, 13.73)). There was little difference in coverage between $\mathrm{HCV}$ status subgroups at most recent interview. Regression analysis also showed reduced odds of insufficient coverage for participants who reported most commonly acquiring syringes from NSPs (as opposed to pharmacies or informal sources) $(\mathrm{AOR}=0.27$ (95\% CIs: 0.09, 0.77)).

Full descriptive and regression results are presented in Table 1.

\section{Coverage pattern group categorisation}

Of participants with valid data for coverage pattern categorisation $(n=322), 162(50 \%)$ were consistently covered, 17 (5\%) were consistently uncovered and 143 (45\%) were inconsistently covered.

Median coverage across interviews for the total cohort was $150-167 \%$. The consistently covered group had greater median levels at every interview wave (214-250 \%); the reverse was true for the consistently uncovered group, who experienced at least a $50 \%$ shortfall in median coverage (45-50\%). Inconsistently covered participants recorded over $100 \%$ median coverage (102-117\%).

Longitudinal median coverage data are presented in Fig. 2.

\section{Correlates of coverage pattern groups at first interview}

Most exposure sub-groups were proportionally similar between coverage pattern groups. However, some significant differences were found.

Those consistently covered were significantly less likely to have receptively shared syringes within the past month $\left(X^{2}=9.58, p=0.008\right)$ than the other coverage pattern groups. They were also significantly more likely to have injecting careers equal to or longer than 13 years $\left(X^{2}=\right.$ $6.58, p=0.037)$ and current OST prescription $\left(X^{2}=12.60\right.$, $p=0.002)$.
In regression analysis, two significant results were found. Those with a current prescription of OST had decreased odds of being classified as inconsistently covered (AOR = 0.41 (95 \% CIs: 0.22, 0.76)), whilst those with a current $\mathrm{HCV}$ infection had increased odds of being classified as inconsistently covered (AOR = 2.73 (95 \% CIs: 1.12, 6.64)) .

Full descriptive and regression results are presented in Table 2.

\section{Discussion}

We conducted longitudinal analysis of individual syringe coverage to address the gap noted in previous research [11] and to better understand the characteristics and predictors of coverage.

We found substantial levels of insufficient coverage. Across interview waves, the percentage of participants experiencing insufficient coverage was between 22-36\%, a finding that accords with previous Australian research $[2,12]$. The fact that, at any time point, between a fifth to a third of the sample have "uncovered" injecting episodes is of serious concern, particularly considering that insufficiently covered participants in this study had a greater tendency to report receptive sharing of syringes, another finding that confirms past research $[2,11]$.

Analysis of longitudinal coverage patterns showed that most participants were consistently able to achieve sufficient coverage across interviews. The levels of insufficient coverage seen at each interview wave were driven then, not by those consistently uncovered but by those who fluctuated between states of coverage over time. This oscillating group should be the focus of interventions designed to reduce insufficient coverage. That so many participants were able to cover themselves at some time points but not at others, suggests a relationship between individual coverage and temporal context, rather than a consistent pattern of deficient coverage.

Cross-sectional analysis revealed that NSP access was associated with higher levels of coverage. This finding is plausible and highlights the advantages of harm reduction services from which PWID can reliably acquire syringes for free. These services overcome the inherent barriers of commercial sources (such as pharmacies) and potentially inconsistent or unreliable sources (such as friends and partners).

The association between insufficient coverage and current HCV infection (RNA positive) was strong. Previous research has shown that knowledge of HCV negativity can moderate injecting risk behaviours, such as receptively sharing syringes or injecting equipment [24]. A similar association between $\mathrm{HCV}$ status and coverage may be hypothesised, whereby a current $\mathrm{HCV}$ infection confers a consequent negligence with regards to sufficient syringe acquisition. Conversely, the shortfall in coverage might be a driver of $\mathrm{HCV}$ transmission. 
Table 1 Analysis of recent sufficient and insufficient coverage at first and most recent interview

\begin{tabular}{|c|c|c|c|c|c|c|c|c|}
\hline & $\begin{array}{l}\text { First interview } \\
<100 \%, n(\%)\end{array}$ & $\begin{array}{l}\text { First interview } \\
\geq 100 \%, n(\%)\end{array}$ & $\begin{array}{l}\text { Chi-squared } \\
p \text {-value }\end{array}$ & $\begin{array}{l}\text { Most recent } \\
\text { interview } \\
<100 \%, n(\%)\end{array}$ & $\begin{array}{l}\text { Most recent } \\
\text { interview } \\
\geq 100 \% \\
\end{array}$ & $\begin{array}{l}\text { Chi-squared } \\
p \text {-value }\end{array}$ & $\begin{array}{l}\text { AOR }^{\mathrm{a}} \text { at first interview, } \\
\text { AOR }(95 \% \mathrm{Cl})\end{array}$ & $\begin{array}{l}\text { AOR } \\
p \text {-value }\end{array}$ \\
\hline \multicolumn{9}{|l|}{ Sex } \\
\hline Female & $27(36 \%)$ & $84(39 \%)$ & 0.673 & $23(32 \%)$ & 81 (38 \%) & 0.393 & 1 & \\
\hline Male & 47 (64 \%) & $130(61 \%)$ & & $47(68 \%)$ & $132(62 \%)$ & & $1.37(0.61,3.09)$ & 0.442 \\
\hline \multicolumn{9}{|l|}{ Indigenous status } \\
\hline No & 66 (92\%) & 200 (93 \%) & 0.606 & 62 (91\%) & 202 (95 \%) & 0.270 & 1 & \\
\hline Yes & $6(8 \%)$ & $14(7 \%)$ & & $6(9 \%)$ & $11(5 \%)$ & & $1.04(0.26,4.20)$ & 0.956 \\
\hline \multicolumn{9}{|c|}{ WHO definition of youth } \\
\hline$\leq 24$ years & $11(15 \%)$ & 41 (19\%) & 0.408 & $3(4 \%)$ & $9(4 \%)$ & 0.983 & 1 & \\
\hline$>24$ years & $63(85 \%)$ & $173(81 \%)$ & & 67 (96 \%) & 204 (96 \%) & & $0.77(0.23,2.51)$ & 0.661 \\
\hline \multicolumn{9}{|c|}{ Highest level of education } \\
\hline$<y r 10$ & $23(31 \%)$ & $63(29 \%)$ & 0.515 & $15(22 \%)$ & $59(28 \%)$ & 0.620 & 1 & \\
\hline Year 10-11 & $26(36 \%)$ & $92(43 \%)$ & & $26(38 \%)$ & $74(35 \%)$ & & $0.56(0.23,1.39)$ & 0.210 \\
\hline $\begin{array}{l}\text { Year 12/higher } \\
\text { educ/trade }\end{array}$ & $24(33 \%)$ & $59(28 \%)$ & & $28(40 \%)$ & $80(37 \%)$ & & $1.61(0.63,4.13)$ & 0.324 \\
\hline \multicolumn{9}{|c|}{ Employment status } \\
\hline No & $63(85 \%)$ & $175(82 \%)$ & 0.511 & $56(80 \%)$ & $168(79 \%)$ & 0.840 & 1 & \\
\hline Yes & $11(15 \%)$ & 39 (18 \%) & & $14(20 \%)$ & 45 (21\%) & & $0.94(0.29,3.01)$ & 0.919 \\
\hline \multicolumn{9}{|l|}{ Weekly income } \\
\hline$<\$ 400$ & 52 (70 \%) & $144(67 \%)$ & 0.635 & 35 (50 \%) & $113(53 \%)$ & 0.657 & 1 & \\
\hline$\geq \$ 400$ & 22 (30 \%) & 70 (33\%) & & $35(50 \%)$ & 100 (47 \%) & & $0.97(0.40,2.35)$ & 0.943 \\
\hline \multicolumn{9}{|c|}{ Stable accommodation } \\
\hline No & $16(22 \%)$ & $31(14 \%)$ & 0.152 & 17 (25\%) & $34(16 \%)$ & 0.104 & 1 & \\
\hline Yes & $58(78 \%)$ & $183(86 \%)$ & & $52(75 \%)$ & 179 (84 \%) & & $1.03(0.39,2.71)$ & 0.956 \\
\hline \multicolumn{9}{|l|}{ Country of birth } \\
\hline Other & 17 (24\%) & $40(19 \%)$ & 0.366 & $18(26 \%)$ & $36(17 \%)$ & 0.081 & 1 & \\
\hline Australia & $55(76 \%)$ & $174(81 \%)$ & & 50 (74 \%) & 177 (83 \%) & & $0.96(0.37,2.46)$ & 0.934 \\
\hline \multicolumn{9}{|l|}{ Injecting career } \\
\hline$<13$ years & $32(45 \%)$ & 96 (45 \%) & 0.951 & $31(46 \%)$ & 45 (21\%) & $<0.001 *$ & 1 & \\
\hline$\geq 13$ years & $40(55 \%)$ & $118(55 \%)$ & & 37 (54 \%) & $168(79 \%)$ & & $0.65(0.28,1.53)$ & 0.325 \\
\hline \multicolumn{9}{|c|}{ Heroin injection (past month) } \\
\hline No & $9(12 \%)$ & $38(18 \%)$ & 0.262 & $10(14 \%)$ & $39(18 \%)$ & 0.440 & 1 & \\
\hline Yes & $65(88 \%)$ & $176(82 \%)$ & & $60(86 \%)$ & $174(82 \%)$ & & $2.30(0.70,7.56)$ & 0.171 \\
\hline \multicolumn{9}{|c|}{ Methamphetamine injection (past month) } \\
\hline No & $40(54 \%)$ & $141(66 \%)$ & 0.069 & $20(29 \%)$ & $118(55 \%)$ & $<0.001^{*}$ & 1 & \\
\hline Yes & $34(46 \%)$ & $73(34 \%)$ & & $50(71 \%)$ & $95(45 \%)$ & & $1.94(0.86,4.39)$ & 0.112 \\
\hline \multicolumn{9}{|c|}{ Hazardous drinking scale score (8 point cut-off) } \\
\hline abstinent & $24(33 \%)$ & $71(33 \%)$ & 0.588 & $28(40 \%)$ & $85(40 \%)$ & 0.675 & 1 & \\
\hline$<8$ points & $27(37 \%)$ & $90(42 \%)$ & & $23(31 \%)$ & $77(36 \%)$ & & $0.82(0.34,1.98)$ & 0.656 \\
\hline$\geq 8$ points & 22 (30 \%) & $52(25 \%)$ & & $20(29 \%)$ & $51(24 \%)$ & & $1.66(0.63,4.36)$ & 0.304 \\
\hline \multicolumn{9}{|c|}{ Current OST prescription } \\
\hline No & $35(47 \%)$ & $86(40 \%)$ & 0.199 & $45(64 \%)$ & $86(40 \%)$ & $0.001 *$ & 1 & \\
\hline Yes & $29(53 \%)$ & $127(60 \%)$ & & $25(36 \%)$ & $127(60 \%)$ & & $1.02(0.49,2.11)$ & 0.952 \\
\hline
\end{tabular}


Table 1 Analysis of recent sufficient and insufficient coverage at first and most recent interview (Continued)

BBV-TRAQ-SV injecting risk scale score (continuous measure)

$\begin{array}{llllllll}\text { Mean } & 8.91 & 6.04 & 0.083 & 9.64 & 5.58 & \mathbf{0 . 0 2 2 *} & 1.01(0.98,1.03)\end{array}$

Receptive sharing (past month)

$\begin{array}{lll}\text { No } & 58(78 \%) & 193(91 \%) \\ \text { Yes } & 16(22 \%) & 20(9 \%)\end{array}$

$0.006^{*}$

$57(81 \%)$

191 (90\%)

0.054

Injecting others (past month)

$\begin{array}{lll}\text { No } & 56(76 \%) & 173(81 \%) \\ \text { Yes } & 18(24 \%) & 41(19 \%)\end{array}$

0.343

$13(19 \%)$

21 (10\%)

$1.01(0.31,3.36)$

0.982

injected by others (past month)

$\begin{array}{lll}\text { No } & 66(89 \%) & 186(87 \%) \\ \text { Yes } & 8(11 \%) & 28(13 \%)\end{array}$

$60(86 \%)$

$184(86 \%)$

$10(14 \%)$

$29(14 \%)$

0.888

1

$1.20(0.47,3.05)$

0.699

jecting more than usual (past six months)

$\begin{array}{lll}\text { No } & 45(61 \%) & 133(62 \%) \\ \text { Yes } & 29(39 \%) & 81(38 \%)\end{array}$

$68(97 \%)$

192 (90 \%)

0.063

2 (3\%)

21 (10\%)

$0.32(0.69,1.50)$

0.148

Solitary injecting $>80 \%$ of the time

$\begin{array}{lll}\text { No } & 48(65 \%) & 152(71 \%) \\ \text { Yes } & 26(35 \%) & 62(29 \%)\end{array}$

38 (54 \%)

144 (68 \%)

$0.039 *$

32 (46\%)

$68(32 \%)$

$1.27(0.59,2.76)$

0.541

Arrest (since last interview)

$\begin{array}{lll}\text { No } & 28(38 \%) & 109(51 \%) \\ \text { Yes } & 46(62 \%) & 104(49 \%)\end{array}$

$0.048^{*}$

$52(74 \%)$

154 (73\%)

0.788

$18(26 \%)$

$58(27 \%)$

$1.43(0.64,3.18)$

0.384

HCV serology status

$\begin{array}{lll}\text { Negative } & 6(10 \%) & 43(24 \%) \\ \text { Positive } & 42(70 \%) & 87(49 \%) \\ \text { Exposed } & 12(20 \%) & 47(27 \%)\end{array}$

$0.012^{*}$

$\begin{array}{ll}6(10 \%) & 19(11 \%) \\ 42(68 \%) & 105(61 \%) \\ 14(22 \%) & 59(28 \%)\end{array}$

0.607

$4.44(1.43,13.73)$

$0.010^{*}$

NSP as usual source of syringe acquisition (past month)

\begin{tabular}{|c|c|c|c|c|c|c|c|c|}
\hline No & $12(16 \%)$ & 20 (9 \%) & 0.105 & $20(29 \%)$ & $31(15 \%)$ & $0.008^{*}$ & 1 & \\
\hline Yes & 62 (84 \%) & 194 (91\%) & & $50(71 \%)$ & $182(85 \%)$ & & $0.27(0.09,0.77)$ & $0.015^{*}$ \\
\hline
\end{tabular}

Regression number of observations: $215 ; \operatorname{Prob}\left(\mathrm{chi}^{2}\right): 0.12 ; R^{2}: 0.14$

*Indicates statistically significant result at the $<0.05$ alpha level (bold data)

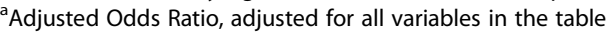

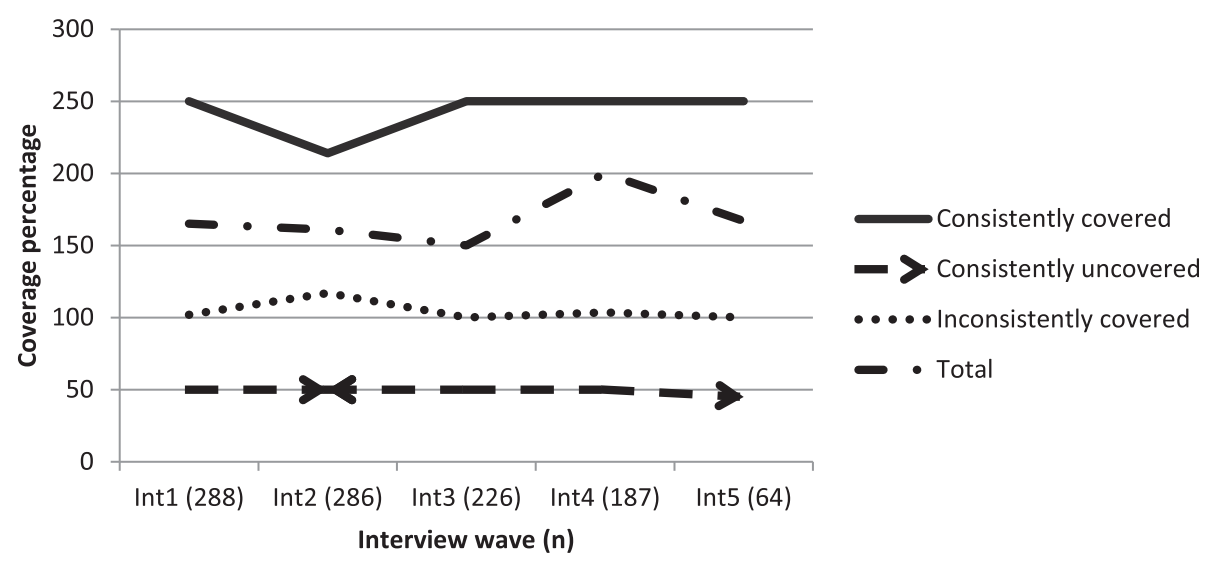

Fig. 2 Median coverage percentage across interview waves by coverage pattern groups 
Table 2 Descriptive and logistic regression analysis of coverage pattern groups at first interview

\begin{tabular}{|c|c|c|c|c|c|c|}
\hline & $\begin{array}{l}\text { Consistently } \\
\text { covered, } n(\%)\end{array}$ & $\begin{array}{l}\text { Consistently } \\
\text { uncovered, } n(\%)\end{array}$ & $\begin{array}{l}\text { Inconsistently } \\
\text { covered, } n(\%)\end{array}$ & $\begin{array}{l}\text { Chi squared } \\
p \text {-value }\end{array}$ & $\begin{array}{l}\text { AOR }^{a} \text { at first interview, } \\
\text { AOR }(95 \% \mathrm{Cl})\end{array}$ & $\begin{array}{l}\text { AOR } \\
p \text {-value }\end{array}$ \\
\hline \multicolumn{7}{|l|}{ Sex } \\
\hline Female & $67(41 \%)$ & $6(35 \%)$ & 49 (34 \%) & 0.433 & 1 & \\
\hline Male & 95 (59 \%) & $11(65 \%)$ & $94(66 \%)$ & & $1.43(0.72,2.83)$ & 0.311 \\
\hline \multicolumn{7}{|l|}{ Indigenous status } \\
\hline No & $152(94 \%)$ & $14(88 \%)$ & 136 (96 \%) & 0.361 & 1 & \\
\hline Yes & $10(6 \%)$ & $2(12 \%)$ & $6(4 \%)$ & & $0.33(0.07,1.62)$ & 0.172 \\
\hline \multicolumn{7}{|l|}{ WHO definition of youth } \\
\hline$\leq 24$ & $22(14 \%)$ & $2(12 \%)$ & $28(19 \%)$ & 0.321 & 1 & \\
\hline$>24$ & 140 (86 \%) & $15(88 \%)$ & $115(81 \%)$ & & $1.50(0.18,1.37)$ & 0.177 \\
\hline \multicolumn{7}{|l|}{ Highest level of education } \\
\hline$<y r 10$ & $53(33 \%)$ & $6(35 \%)$ & $36(25 \%)$ & 0.613 & 1 & \\
\hline yr 10-11 & $64(39 \%)$ & $6(35 \%)$ & $66(47 \%)$ & & $1.73(0.82,3.62)$ & 0.148 \\
\hline yr 12/higher educ/trade & $45(28 \%)$ & $5(30 \%)$ & $40(28 \%)$ & & $2.14(0.92,5.01)$ & 0.078 \\
\hline \multicolumn{7}{|l|}{ Employment status } \\
\hline No & 125 (77 \%) & $15(88 \%)$ & $118(83 \%)$ & 0.348 & 1 & \\
\hline Yes & $37(23 \%)$ & $2(12 \%)$ & $25(17 \%)$ & & $0.91(0.37,2.23)$ & 0.838 \\
\hline \multicolumn{7}{|l|}{ Weekly income } \\
\hline$<\$ 400$ & 109 (68 \%) & 10 (59 \%) & 101 (71 \%) & 0.581 & 1 & \\
\hline$\geq \$ 400$ & $52(32 \%)$ & 7 (41 \%) & $42(29 \%)$ & & $1.01(0.48,2.13)$ & 0.976 \\
\hline \multicolumn{7}{|l|}{ Stable accommodation } \\
\hline No & $21(13 \%)$ & $2(12 \%)$ & $22(15 \%)$ & 0.801 & 1 & \\
\hline Yes & 141 (87 \%) & 15 (88 \%) & $121(85 \%)$ & & $1.03(0.44,2.41)$ & 0.946 \\
\hline \multicolumn{7}{|l|}{ Country of birth } \\
\hline Other & $24(15 \%)$ & 5 (31\%) & $29(20 \%)$ & 0.169 & 1 & \\
\hline Australia & $138(85 \%)$ & $11(69 \%)$ & $113(80 \%)$ & & $0.93(0.38,2.25)$ & 0.873 \\
\hline \multicolumn{7}{|l|}{ Injecting career } \\
\hline$<13$ years & $58(36 \%)$ & $8(50 \%)$ & $71(50 \%)$ & $0.037^{*}$ & 1 & \\
\hline$\geq 13$ years & $104(64 \%)$ & $8(50 \%)$ & $71(50 \%)$ & & $0.62(0.30,1.25)$ & 0.181 \\
\hline \multicolumn{7}{|c|}{ Heroin injection (past month) } \\
\hline No & $41(25 \%)$ & $2(12 \%)$ & $24(17 \%)$ & 0.120 & 1 & \\
\hline Yes & $121(75 \%)$ & $15(88 \%)$ & $119(83 \%)$ & & $1.26(0.47,3.34)$ & 0.645 \\
\hline \multicolumn{7}{|c|}{ Methamphetamine injection (past month) } \\
\hline No & $108(67 \%)$ & $11(65 \%)$ & $92(64 \%)$ & 0.910 & 1 & \\
\hline Yes & $54(33 \%)$ & $6(35 \%)$ & $51(36 \%)$ & & $0.93(0.46,1.87)$ & 0.842 \\
\hline \multicolumn{7}{|c|}{ Hazardous drinking scale score (8 point cut-off) } \\
\hline abstinent & $53(33 \%)$ & $5(29 \%)$ & $41(29 \%)$ & 0.827 & 1 & \\
\hline$<8$ points & $69(43 \%)$ & $9(53 \%)$ & $62(44 \%)$ & & $1.17(0.57,2.40)$ & 0.673 \\
\hline$\geq 8$ points & $39(24 \%)$ & $3(18 \%)$ & $39(27 \%)$ & & $1.42(0.59,3.42)$ & 0.437 \\
\hline \multicolumn{7}{|l|}{ Current OST prescription } \\
\hline No & $54(33 \%)$ & $11(65 \%)$ & $72(50 \%)$ & $0.002^{*}$ & 1 & \\
\hline Yes & $108(67 \%)$ & $6(35 \%)$ & $71(50 \%)$ & & $0.41(0.22,0.76)$ & $0.005^{*}$ \\
\hline \multicolumn{7}{|c|}{ BBV-TRAQ-SV injecting risk scale score (continuous measure) } \\
\hline Mean & 6.03 & 9.88 & 5.96 & 0.293 & $0.97(0.97,1.02)$ & 0.776 \\
\hline
\end{tabular}


Table 2 Descriptive and logistic regression analysis of coverage pattern groups at first interview (Continued)

\begin{tabular}{|c|c|c|c|c|c|c|}
\hline \multicolumn{7}{|c|}{ Receptive sharing (past month) } \\
\hline No & 150 (93\%) & $12(71 \%)$ & $124(87 \%)$ & \multirow[t]{2}{*}{$0.008^{*}$} & 1 & \\
\hline Yes & $11(7 \%)$ & $5(29 \%)$ & $19(13 \%)$ & & $1.10(0.36,3.35)$ & 0.865 \\
\hline \multicolumn{7}{|c|}{ Injecting others (past month) } \\
\hline No & $137(85 \%)$ & $13(76 \%)$ & $119(83 \%)$ & \multirow[t]{2}{*}{0.686} & 1 & \\
\hline Yes & $25(15 \%)$ & $4(24 \%)$ & $24(17 \%)$ & & $0.97(0.40,2.32)$ & 0.945 \\
\hline \multicolumn{7}{|c|}{ Injected by others (past month) } \\
\hline No & $145(90 \%)$ & $16(94 \%)$ & $128(90 \%)$ & \multirow[t]{2}{*}{0.830} & 1 & \\
\hline Yes & $17(10 \%)$ & $1(6 \%)$ & $15(10 \%)$ & & $1.66(0.44,6.23)$ & 0.452 \\
\hline \multicolumn{7}{|c|}{ Injecting more than usual (past six months) } \\
\hline No & 107 (66 \%) & $12(71 \%)$ & $88(62 \%)$ & \multirow[t]{2}{*}{0.625} & 1 & \\
\hline Yes & $54(34 \%)$ & $5(29 \%)$ & $54(38 \%)$ & & $1.55(0.80,3.00)$ & 0.191 \\
\hline \multicolumn{7}{|c|}{ Solitary injecting $>80 \%$ of the time } \\
\hline No & $101(67 \%)$ & $8(50 \%)$ & $96(71 \%)$ & \multirow[t]{2}{*}{0.240} & 1 & \\
\hline Yes & $50(33 \%)$ & $8(50 \%)$ & $40(29 \%)$ & & $0.99(0.50,1.96)$ & 0.985 \\
\hline \multicolumn{7}{|c|}{ Arrest (since last interview) } \\
\hline No & $89(55 \%)$ & $6(35 \%)$ & $64(45 \%)$ & \multirow[t]{2}{*}{0.090} & 1 & \\
\hline Yes & $45(45 \%)$ & $11(65 \%)$ & $79(55 \%)$ & & $1.28(0.68,2.40)$ & 0.439 \\
\hline \multicolumn{7}{|c|}{ HCV serology status } \\
\hline Negative & $27(21 \%)$ & $2(17 \%)$ & $16(14 \%)$ & \multirow[t]{3}{*}{0.451} & 1 & \\
\hline Positive & $65(50 \%)$ & $8(66 \%)$ & $68(61 \%)$ & & $2.73(1.12,6.64)$ & $0.027^{*}$ \\
\hline Exposed & 37 (29 \%) & $2(17 \%)$ & $28(25 \%)$ & & $2.31(0.87,6.13)$ & 0.093 \\
\hline \multicolumn{7}{|c|}{ NSP as usual source of syringe acquisition (past month) } \\
\hline No & $14(9 \%)$ & $4(25 \%)$ & $18(13 \%)$ & \multirow[t]{2}{*}{0.149} & 1 & \\
\hline Yes & 137 (91 \%) & $12(75 \%)$ & $120(87 \%)$ & & $0.96(0.36,2.54)$ & 0.933 \\
\hline
\end{tabular}

Regression number of observations: 212; Prob(chi2): $0.25 ; \mathrm{R}^{2}: 0.10$

*Indicates statistically significant result at the $<0.05$ alpha level (bold data)

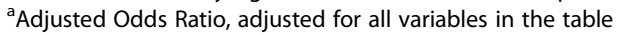

We identified a persistent association between coverage and OST prescription. Cross-sectionally, those with a current OST prescription had significantly higher proportions of sufficient coverage (an outcome Bluthenthal et al. [11] also identified), and longitudinally, current OST prescription was significantly associated with being in the "consistently covered" group. We suspect that the key driver here is the efficacy of OST in reducing opiate use $[20,25]$. Receipt of OST has been shown to reduce the risk of $\mathrm{HCV}$ incidence amongst Australian heroin injecting PWID almost five-fold [26], whilst internationally, combined OST prescription with sufficient individual-level coverage (termed "full harm reduction") has been associated with an almost $80 \%$ decrease in the risk of HCV acquisition [27]. The role of OST prescription in reducing HCV transmission is reflective of a reduction in injecting risk. Subsequently, the expansion of OST provision may play an important role in increasing coverage levels. Victorian OST services, however, are currently hampered by insufficient prescribers and inefficiencies in service co-ordination [28]. Increasing the numbers of PWID in receipt of OST would require strategies to overcome these barriers.

Though Australia's harm reduction provision is comprehensive, with at least one source of syringe distribution per 30 PWID [16], the proportions of insufficient coverage in this and similar Australian research [2, 12, 17] indicate ongoing shortfalls. One explanation is that the PWID population is dynamic and diverse. The variance in individual coverage is undoubtedly due to more factors than we've captured here (as evidenced by the regression model's low $\mathrm{R}^{2}$ value). To appropriately account for this diversity, harm reduction services must be adaptive and flexible. Consequently, the acquisition of sterile syringes should be facilitated as much as possible by expanding hours of NSP operation and implementing novel methods of syringe distribution (such as syringe vending machines, which are not widely available in 
Melbourne) [29-31]. NSPs are an efficacious, costeffective means of limiting disease spread [14, 32, 33], and recent modelling suggests increases in service coverage would decrease BBV prevalence [34, 35].

Finally, research on individual coverage levels highlight the inadequacy of population-level measurements (such as the WHO measure). Though logistically difficult to determine, individual-level measurements capture the micro-details of coverage that are often diluted in population-wide averages. For example, at first interview in our cohort, 14,525 syringes were reportedly acquired by 338 currently injecting participants within the two weeks before interview, or an average of 43 syringes per person. If this average was multiplied by 26 to extrapolate to the total weeks in the year, this equals 1118 syringes per PWID, nearly six times the WHO recommendation for syringe distribution to curtail HIV spread [6]. However, it is clear that in aggregate, the PWID who cover their injecting episodes mask those who do not, and those who do not cover themselves are at most risk.

\section{Limitations}

To measure individual levels of coverage, separate parameters are required, all prone to reporting bias. Such a limitation is an unavoidable element of this field of study [11, 12]. However, PWID recall reliability has been demonstrated [36], and we chose the past two weeks as the recall period for the questions to minimise recall bias.

Recent research has shown that many PWID exploit Australia's unlimited dispensation policy and stockpile syringes for future use [17], meaning that participants who reported no past two-week syringe acquisition may still have been sufficiently covered. These findings came after MIX survey development and we were unable to account for stockpiling in our dataset. However, McCormack et al. found that the inclusion of a stockpiling question decreased levels of insufficient coverage (also using Bluthenthal et al.'s measure) by only eight percentage points (24 to $16 \%$ ) across their sample [17], so we are confident in the patterns we observed.

A substantial amount of coverage data was missing from our dataset. Approximately $45 \%$ of our observations lacked coverage data, mostly $(72 \%)$ due to past week injection abstinence. However, the remaining $28 \%$ of missing data was due to no reported syringe acquisition within the past two weeks and, with many of these participants also reporting injecting (sometimes in significant frequencies), syringe stockpiling was probably occurring. Therefore, we restricted analysis to those participants reporting both injecting and concurrent syringe acquisition.
Finally, our participants were recruited from a population with unknown parameters, limiting the generalisability of our findings [37].

\section{Conclusion}

We explored individual needle and syringe coverage longitudinally. We replicated previous Australian research and found substantial insufficient coverage amongst our group. This coverage shortfall is driven mainly by participants who cover themselves intermittently, suggesting the influence of temporal factors. Statistical analysis showed the protective effects of current OST prescription and NSPs as the main source of syringe acquisition, and an increased risk for those currently infected with HCV. An increase in OST coverage would potentially see a concurrent increase in syringe coverage, whilst more generally, to ensure PWID have every opportunity to avoid BBV infections and other injecting-related problems, the best response is the general expansion of NSP services.

\section{Additional files}

Additional file 1: Appendix 1. Demographic comparison between total and amended MIX samples at first interview. Comparative statistics between the full MIX cohort and the amended cohort used in this analysis. (DOCX 14 kb)

Additional file 2: Amended MIX questionnaire for longitudinal coverage analysis. Selected questions from the MIX questionnaire, relevant to the analysis within this article. Variables are presented in their original state, prior to data cleaning. (DOCX $22 \mathrm{~kb}$ )

\section{Acknowledgments}

The authors wish to thank the participants of the MIX study along with the staff of the community based organizations who assisted with recruitment. Thank you to members of the MIX study team who assisted with participant recruitment, follow up and interviewing.

\section{Funding}

The MIX study was funded by The Colonial Foundation Trust and the National Health and Medical Research Council (NHMRC Grant \#545891). DO'K receives support from the NHMRC through a postgraduate scholarship. PD is an NHMRC Senior Research Fellow. The authors gratefully acknowledge the contribution to this work of the Victorian Operational Infrastructure Support Program's support of the Burnet Institute. The funding bodies played no role in the study design, data analysis or preparation of the manuscript for publication.

Availability of data and materials

Data cannot be shared for this study due to the highly confidential nature of the data, obtained from a vulnerable, marginalised population.

\section{Authors' contributions}

DO'K led the analysis and writing of the article. NS, CA \& PD assisted with conceptualisation and provided essential input and support during analysis and writing. All authors have read the article and approve of its submission to BMC Health Services Research.

\section{Competing interests}

PD has received funding from Gilead Sciences Inc and Reckitt Benckiser for work unrelated to this study. Other authors have nothing to declare.

Consent for publication

Not applicable. 


\section{Ethics approval and consent to participate}

The Victorian Department of Health Human Research Ethics Committee and the Monash University Human Research Ethics Committee approved the study. All participants provided informed consent to be involved in the study. Reference number 28/13.

Received: 22 April 2016 Accepted: 12 August 2016

Published online: 19 August 2016

\section{References}

1. Jolley E, Rhodes T, Platt L, Hope V, Latypov A, Donoghoe M, et al. HIV among people who inject drugs in Central and Eastern Europe and Central Asia: a systematic review with implications for policy. BMJ Open. 2012;2(5).

2. Bryant J, Paquette D, Wilson H. Syringe coverage in an Australian setting: does a high level of syringe coverage moderate syringe sharing behaviour? AIDS Behav. 2012;16(5):1156-63.

3. Marshall BD, Shoveller JA, Wood E, Patterson TL, Kerr T. Difficulty accessing syringes mediates the relationship between methamphetamine use and syringe sharing among young injection drug users. AIDS Behav. 2011;15(7): 1546-53.

4. Pouget ER, Deren S, Fuller C, Blaney S, McMahon JM, Kang S, et al. Receptive syringe sharing among injection drug suers in Harlem and the Bronx during New York state expanded syringe access demonstration program. J Acquir Immune Defic Syndr Hum Retrovirol. 2005;39(4):471-7.

5. MacArthur GJ, van Velzen E, Palmateer N, Kimber J, Pharris A, Hope V, et al. Interventions to prevent HIV and Hepatitis C in people who inject drugs: a review of reviews to assess evidence of effectiveness. Int J Drug Policy. 2014;25(1):34-52.

6. WHO. Technical guide for countries to set targets for universal HIV services for injecting drug users. Geneva: World Health Organisation; 2012.

7. Burrows D. Advocacy and coverage of needle exchange programs: results of a comparative study of harm reduction programs in Brazil, Bangladesh, Belarus, Ukraine, Russian Federation and China. Cad Saude Publica. 2006; 22(4):871-9.

8. Bluthenthal RN, Ridgeway G, Schell T, Anderson R, Flynn NM, Kral AH. Examination of the association between syringe exchange program (SEP) dispensation policy and SEP client-level syringe coverage among injection drug users. Addiction. 2007;102(4):638-46.

9. Walensky RP, Losina E, Malatesta L, Barton GE, O'Connor CA, Skolnik PR, et al. Effective HIV case identification through routine HIV screening at urgent care centers in Massachusetts. Am J Public Health. 2005;95(1):71-3.

10. Cooper HLF, Des Jarlais DC, Ross Z, Tempalski B, Bossak B, Friedman SR. Spatial access to syringe exchange programs and pharmacies selling overthe-counter syringes as predictors of drug injectors' use of sterile syringes. Res Pract. 2011;101(6):1118-25.

11. Bluthenthal RN, Anderson R, Flynn NM, Kral AH. Higher syringe coverage is associated with lower odds of HIV risk and does not increase unsafe syringe disposal among syringe exchange program clients. Drug Alcohol Depend. 2007;89(2-3):214-22

12. Iversen J, Topp $L$, Wand $H$, Maher $L$. Individual-level syringe coverage among Needle and Syringe Program attendees in Australia. Drug Alcohol Depend. 2012;122(3):195-200.

13. Shaw SY, Shah L, Jolly AM, Wylie JL. Determinants of injection drug user (IDU) syringe sharing: the relationship between availability of syringes and risk network member characteristics in Winnipeg, Canada. Addiction. 2007; 102(10):1626-35.

14. Wodak A, Cooney A. Do needle syringe programs reduce HIV infection among injecting drug users: a comprehensive review of the international evidence. Subst Use Misuse. 2006;41(6-7):777-813.

15. Kwon JA, Anderson J, Kerr CC, Thein HH, Zhang L, Iversen J, et al. Estimating the cost-effectiveness of needle-syringe programs in Australia. AIDS. 2012; 26(17):2201-10.

16. IHRA. Global state of harm reduction. London, United Kingdon: International Harm Reduction Association, 2014.

17. McCormack A, Aitken C, Burns LA, Cogger S, Dietze P. Syringe stockpiling by people who inject drugs: an evaluation of current measures for needle and syringe program coverage. Am J Epidemiol. 2015;183(9):852-60.

18. Horyniak D, Higgs P, Jenkinson R, Degenhardt L, Stoove M, Kerr T, et al. Establishing the Melbourne injecting drug user cohort study (MIX): rationale, methods, and baseline and twelve-month follow-up results. Harm Reduction J. 2013;10(11).
19. Sacks-Davis R, Daraganova G, Aitken C, Higgs P, Tracy L, Bowden S, et al. Hepatitis $C$ virus phylogenetic clustering is associated with the social-injecting network in a cohort of people who inject drugs. PLoS One. 2012;7(10):e47335.

20. Scott N, Caulkins JP, Ritter A, Dietze P. How patterns of injecting drug use evolve in a cohort of people who inject drugs. Trends \& issues in crime and criminal justice. 2015;502:1-7.

21. O'Keefe D, Horyniak D, Dietze P. From initiating injecting drug use to regular injecting: Retrospective survival analysis of injecting progression within a sample of people who inject drugs regularly. Drug Alcohol Depend. 2015;158:177-80.

22. Babor TF, Higgins-Biddle JC, Saunders JB, Monteiro MG. The alcohol use disorders identification test: guidelines for use in primary care. 2nd ed. Geneva: World Health Organisation; 2001.

23. Stoove M, Fry CL. The Blood Borne Virus Transmission Risk Assessment Questionnaire - Short Version (BBV-TRAQ-SV): Administration and Procedures Manual. Victoria: Turning Point Alcohol and Drug Centre Inc; 2006.

24. Palmateer N, Anderson N, Wadd S, Hutchinson S, Taylor A, Goldberg D. Exploring associations between perceived HCV status and injecting risk behaviors among recent initiates to injecting drug use in Glasgow. Subst Use Misuse. 2008;43(3-4):375-88.

25. Amato L, Davoli M, Perucci CA, Ferri M, Faggiano F, Mattick RP. An overview of systematic reviews of the effectiveness of opiate maintenance therapies: available evidence to inform clinical practice and research. J Subst Abuse Treat. 2005;28:321-9.

26. White B, Dore GJ, Lloyd AR, Rawlinson WD, Maher L. Opioid substitution therapy protects against hepatitis $C$ virus acquisition in people who inject drugs: the HITS-c study. Med J Aust. 2014;201(6):326-9.

27. Turner KM, Hutchinson S, Vickerman P, Hope V, Craine N, Palmateer N, et al. The impact of needle and syringe provision and opiate substitution therapy on the incidence of hepatitis C virus in injecting drug users: pooling of UK evidence. Addiction. 2011;106(11):1978-88.

28. King T, Ritter A, Berends L. Victorian Pharmacotherapy Review. Sydney: National Drug and Alcohol Research Centre; 2011.

29. Islam MM, Conigrave KM. Syringe vending machines as a form of needle syringe programme: advantages and disadvantages. J Substance Use. 2007; 12(3):203-12.

30. Wood E, Kerr T, Small W, Jones J, Schechter MT, Tyndall MW. The impact of police presence on access to needle exchange programs. J Acquir Immune Defic Syndr. 2003;34(1):116-7.

31. Islam MM, Conigrave KM. Assessing the role of syringe dispensing machines and mobile van outlets in reaching hard-to-reach and high-risk groups of injecting drug users (IDUs): a review. Harm Reduct J. 2007:4:14.

32. Strathdee SA, Vlahov D. The effectiveness of needle exchange programs: a review of the science and policy. AIDScience. 2001;1(16).

33. Laufer FN. Cost-effectiveness of syringe exchange as an HIV prevention strategy. Acquir Immune Defic Syndr. 2001;28:272-8.

34. Vickerman P, Martin N, Turner K, Hickman M. Can needle and syringe programmes and opiate substitution therapy achieve substantial reductions in hepatitis $C$ virus prevalence? Model projections for different epidemic settings. Addiction. 2012;107(11):1984-95.

35. Vickerman P, Hickman M, Rhodes T, Watts C. Model projections on the required coverage of syringe distribution to prevent HIV epidemics among injecting drug users. Epidemiol Soc Sci. 2006;42(3):355-61.

36. Darke S. Self-report among injecting drug users: a review. Drug Alcohol Depend. 1998;51:252-63.

37. Horyniak D, Stoove M, Degenhardt L, Aitken C, Kerr T, Dietze P. How do drug market changes affect characteristics of injecting initiation and subsequent patterns of drug use? Findings from a cohort of regular heroin and methamphetamine injectors in Melbourne, Australia. Int J Drug Policy. 2015;26(1):43-50. 